\title{
A review of complementary therapies for chemotherapy induced gastrointestinal mucositis
}

\author{
Raja A.H Kuchay* \\ School of Biosciences \& Biotechnology, CBS, BGSB University, J\&K, India.
}

\begin{abstract}
Summary Administration of chemotherapy often leads to gastrointestinal mucositis (GIM). GIM manifests as nausea, abdominal pain and diarrhoea in recipients of chemotherapy. GIM is a major complication occurring in approximately $80 \%$ of patients receiving 5 -flurouracil treatment. These side-effects may become so severe that significant dose reductions are required, ultimately affecting treatment efficacy and patient survival. Complementary and alternative medicine (CAM) is a growing area of public interest. This review will provide an overview of current knowledge of complementary medicinal therapies for chemotherapy induced GIM. An understanding of this evolving literature is useful in discussing these therapies with patients who are considering using them.
\end{abstract}

Keywords: Mucositis, intestine, complementary medicine

\section{Introduction}

The fast-renewing intestinal epithelium is vulnerable to the cytotoxicity of chemotherapy. Cytotoxic agents used during chemotherapy are effective at killing cancerous cells however they also indiscriminately target certain healthy tissue. Chemotherapy-induced gastrointestinal mucositis (GIM) is a dose-limiting side effect of many chemoagents. It has been pathologically described as an intestinal inflammation characterized by an early event of epithelia apoptosis (1-3). GIM is a major oncological problem, caused by the treatment of malignant disease with chemotherapeutic agents. It affects the entire gastrointestinal tract and causes pain and ulceration in the mouth as well as abdominal bloating, vomiting and diarrhoea in the small and large intestines $(4,5)$. After treatment with standard dose chemotherapy, approximately $40 \%$ of all patients and up to $100 \%$ of patients undergoing high-dose chemotherapy with bone marrow or stem cell transplantation reportedly develop GIM (4-6). GIM and its associated complications lead to a dose reduction of chemotherapy and compromises overall survival in cancer patients. GIM adds substantial

Released online in J-STAGE as advance publication October $17,2016$.

*Address correspondence to:

Dr. Raja A.H Kuchay, School of Biosciences \& Biotechnology, CBS, BGSB University, J\&K, 185234, India.

E-mail: kuchay_bgsbu@yahoo.com burden on the medical care required for cancer patients, increases healthcare costs and reduces patient quality of life (7). Current therapies for treatment of GIM are suboptimal and potentially toxic. There is an acute need for the development of more effective treatment strategies for chemotherapy-induced GIM. Emerging evidence suggests that complementary and alternative medicine (CAM) based therapeutic modalities are highly effective in modulating the immune system, disrupting the proinflammatory cascade and restoring digestive health while improving patient's quality of life. In this context we will review some of the complementary medicine based therapeutics for treatment of GIM. However, before going into these details, it is necessary to understand the architecture of small intestine and current molecular model for pathobiology of GIM.

\section{Small intestinal architecture}

GIM has been attributed to the high proliferation rate in the intestine that is interrupted and reduced by chemotherapy drugs, and also to direct killing of crypt cells (4-6). The intestinal epithelium is the largest of the body's mucosal surfaces, covering $\sim 400 \mathrm{~m}^{2}$ of surface area with a single layer of cells organized into crypts and villi. This surface is continually renewed by pluripotent intestinal epithelial stem cells that reside in the base of crypts, where the pro-liferation, differentiation and functional potential of epithelial cell 
progenitors is regulated by the local stem cell niche $(8-10)$. The epithelial layer of the GI tract is a rapidly renewing tissue with a high cell turnover rate. Stem cells in the lower half of the crypts give rise to daughter cells, thereby producing all the cells of the epithelium. Newly produced cells migrate out of the crypts up to the villus or migrate downward into the base of the crypts and reside under or between the stem cells. During migration up to the villus, most cells differentiate into functional enterocytes (11). It is generally accepted that once epithelial cells complete their migration along the crypt-villous axis they are sloughed off into the lumen. This rapid turnover of cells explains why the GI tract is particularly susceptible to the effects of cytotoxic agents (12). Despite the different sites of action of various chemoagents, the end result is intestinal crypt hyperplasia $(4,5)$. The epithelial stem cells in the small intestine become damaged and no longer divide or differentiate into specific cell lineages following chemotherapy leading to a rapid loss of structure and function (13).

\section{Pathobiology of GIM}

In the last decade, significant progress has been made in understanding the pathobiology of GIM. It has been postulated that GIM occurs in five overlapping phases: initiation, up-regulation and message generation, signalling and amplification, ulceration and healing (14-16). Upon anti-cancer treatment, both DNA and non-DNA damages occur. DNA strand breaks cause direct injury in cells of the basal epithelium. At the same time, reactive oxygen species (ROS) are formed, starting downstream biological events. Nuclear factor kappa B (NFkB), cyclooxygenase-2 (COX-2) as well as pro-inflammatory cytokines like interleukin-6 (IL6 ), interleukin-1 $\beta$ (IL-1 $\beta$ ) and tumour-necrosis factor (TNF) have been suggested to play a key role in the development of GIM (17-20). These overlapping steps are thought to be largely driven by the activation of $\mathrm{NF} \kappa \mathrm{B}$, subsequently promoting key pro-inflammatory cytokines. Furthermore, apoptosis, pathogenic bacteria, inflammation, matrix metalloproteinases (MMPs), loss of mucosal barrier integrity and toll like receptors (TLRs) have also been reported to play an important role in GIM (21-28).

There is evidence that chemotherapy can induce GIM through various pathways. The timing of histological lesions, peak tissue levels of NF $\kappa B$ and pro-inflammatory cytokines are different according to the chemotherapy agents like irinotecan, methotrexate (MTX) or 5-fluorouracil (5-FU) (29). Commensal bacteria play an important role in intestinal homoeostasis, and have some protective effect on the intestinal integrity. Their interactions with TLRs and subsequent activation of NF $\kappa \mathrm{B}$ signalling pathway contributes to intestinal homoeostasis, maintaining the barrier function and promoting wound repair and tissue regeneration $(30,31)$. TLRs initiate the innate immune response and the production of proinflammatory mediators including IL- $1 \beta$, nitric oxide and IL-18, whose role in intestinal GIM is well known (32-34). Recently, TLR/MyD88/NF- $\mathrm{B}$ pathway has been implicated in the mechanisms of damage involved in chemotherapy-related GIM (27). It has also been reported that TLR-2 acts as a central regulator of xenobiotic defense and targeting TLR2 may represent a novel therapeutic approach in chemotherapy-induced GIM (26).

Role of platelet-activating factor (PAF) in chemotherapy-induced GIM has also been reported (35). NADPH oxidase 1 (NOX1) has also been suggested to be involved in pathogenesis of GIM (36). Furthermore, role of NOX-2 mediated inflammasome activation and inflammasome-dependent production of IL$1 \beta$ and IL-18 has also been verified (37). The mucin layer is an integral component of barrier function in the intestine and chemotherapy agents significantly decreased epithelial mucin levels in the jejunum of rats (38). Findings strongly suggest chemotherapy causes tight junction defects which lead to mucosal barrier dysfunction and the development of GIM (23). Thus, it is quite clear that pathobiology of GIM involves many signalling pathways and diverse range of molecules.

Given the literature summarised above, it is clear that some kind of preventative therapy is required for GIM in patients receiving cancer chemotherapy treatment. In many cases of cancer chemotherapy the treatment needs to be discontinued due to high incidence of GIM, risking the life of patients. CAM is widely used, particularly for chronic medical conditions that are difficult to treat. Because only a limited number of treatments are available for GIM, many patients can opt for CAM. Two of the most important CAM therapeutic modalities for chemotherapy induced GIM are based on plants and probiotics.

\section{Plant based complementary therapies}

Aged garlic extract (AGE) administration has been reported to decrease the severity of jejunal damage against MTX-induced GIM in the small intestine of rats $(39,40)$. MTX induced apoptosis of IEC-6 cells was shown to be depressed by AGE (41). The MTX-induced loss of viable IEC-6 cells was almost completely prevented by the presence of more than $0.1 \%$ AGE (41). Grape seed extract (GSE) represent a new therapeutic option to decrease the symptoms of GIM. Compared with 5-FU controls, GSE significantly decreased the histological damage score, increased jejunal crypt depth, attenuated the chemotherapyinduced reduction of mucosal thickness and decreased myeloperoxidase activity in rat models of GIM $(42,43)$. GSE has also been reported to improves epithelial 
structure, intestinal epithelial differentiation and suppress inflammation in ileum of IL-10-deficient mice $(44,45)$. Grapes are rich in polyphenols that vary in their distribution inside the grapes with less than $10 \%$ in the pulp, $60-70 \%$ deposited in seeds, and $20-35 \%$ in the skin (46). Proanthocyanidins are believed to be the key bioactive constituents in GSE (47). Administration of proanthocyanidin decreased the jejunal damage and malondialdehyde level, which were caused by MTX treatment and increased superoxide dismutase and glutathione peroxidase levels in rats $(48,49)$.

It has been reported that apricot and beta-carotene treatment may protect the impairment of oxidative stress and ameliorate MTX-induced intestine damage at biochemical and histological levels (50). Single or combined application of apricot and beta-carotene ameliorated the effects like fusion and shortening in the villus, epithelial desquamation, crypt loss, inflammatory cell infiltration in the lamina propria, goblet cell depletion and microvillar damage in the small intestine of rats treated with MTX (50). Administration of Vitamin A is also known to decrease the MTX-induced damage to the small intestine (51). Ellagic acid (EA) and pumpkin seed oil (PSO) have been suggest to protect the small intestine of rats from MTX-induced damage through their antioxidant and anti-inflammatory effects (52). Administration of EA and PSO decreased the intestinal damage, prostaglandin E2 and nitric oxide level (52). Hesperidin, a flavanone glycoside mainly found in citrus fruits has been reported to prevent intestinal epithelial injury resulting from chemotherapy treatment (53). The small intestinal damage score, inducible nitric oxide synthase and interleukin- 8 levels were lower MTX plus hesperidin group (53).

Aqueous extract of Chimonanthus nitens var. salicifolius (CS), a traditional Chinese herb has been found to be beneficial against 5-FU induced GIM in mice (54). CS attenuated the subsequent body weight loss, diarrhea, and faecal blood, reducing the hepatic injury, and maintaining both intestinal length and villus structure (54). Downregulation of apoptotic gene caspase 3 in CS group compared with mice treated with 5-FU only was reported (54). CS aqueous extract treatments suppressed the elevation of TNF- $\alpha$ induced by 5-FU challenge. Furthermore, other cytokines, including IL- $1 \beta$ and IL-12b, were also inhibited by CS treatment, suggesting an anti-inflammatory effect of CS (54). Three flavonoids rutin, quercetin, and kaempferol were identified by HPLC to be abundant in the aqueous extract of CS (54). Rutin is considered as a powerful antioxidant with pharmacological benefits including antitumor, antiinflammatory, and anti-diarrhoeal effects $(55,56)$.

Curcumin has been reported to significantly reverse chemotherapy-induced weight-loss and damage to intestinal mucosa (57). Curcumin also reduced the expression of pro-apoptotic Bax but stimulated antiapoptotic Bcl-2 to attenuate 5-FU-induced apoptosis of intestinal epithelial cells (57). Curcumin decreased the levels of ICAM-1, IL- $1 \beta$ and TNF- $\alpha$, but increased the levels of IL-10 and SOD in rat models of GIM (58). Furthermore, mitogen-activated protein kinase phosphatase-1 (MKP-1) was activated but phospho-p38 was inhibited by curcumin (58). Curcumin also repressed $\mathrm{I}-\mathrm{\kappa B}$ and interfered with the translocation of NF- $\mathrm{\kappa B}$ into nucleus (58). These findings suggest that curcumin, with anti-inflammatory and anti-oxidant activities may be used as an effective reagent for protecting intestinal mucosa barrier during chemotherapy-induced GIM (58). Administration of beta-glucan following MTX has been reported to attenuate the tissue damage (59). Stimulation index, an indicator of oxidative burst in the neutrophils, was decreased by MTX, while betaglucan abolished this effect (59). Furthermore, increased leukocyte apoptosis and cell death in MTX-treated animals were inhibited by beta-glucan. These findings suggest that beta-glucan, through its antioxidant and immunoregulatory effects, may be of therapeutic value in alleviating the leukocyte apoptosis, oxidative tissue injury and thereby the intestinal and hepato-renal side effects of MTX treatment (59).

Saireito, a traditional Japanese herbal medicine and a combined formulation of two herbal medicines (shosaikoto and goreisan) reduced 5-FU-induced GIM through reduction of apoptosis in the intestinal crypt via suppression of the up-regulation of inflammatory cytokines (60). Administration of saireito significantly suppressed the activation of caspase- 3 and reduced 5-FU-increased apoptotic cells, with an inhibition rate of $67.8 \%(60)$. Furthermore, it significantly attenuated the up-regulation of both TNF- $\alpha$ and IL-1 $\beta$ mRNA induced by 5 -FU. The inhibition rate was 72.5 and $77.6 \%$ for TNF- $\alpha$ and IL-1 $\beta$, respectively (60). Iberogast, a mixture of extracts from bitter candytuft (Iberis amara), angelica root (Angelicae radix), milk thistle fruit (Silybi mariani fructus), celandine herb (Chelidonii herba), caraway fruit (Carvi fructus), liquorice root (Liquiritiae radix), peppermint herb (Menthae piperitae folium), balm leaf (Melissae folium) and chamomile flower (Matricariae flos) partially improved the histopathological features of 5-FU induced GIM in rats $(61,62)$. Acteoside, a phenylpropanoid glycoside derived from plant species in the Scrophularia genus alleviated MTX-induced small intestinal mucositis possibly by preventing inflammation $(63,64)$. Mucoadhesive formulation of Bidens pilosa L. (Asteraceae) has recently been reported to reduce intestinal injury from 5-FU induced GIM in mice (65). Plant based complementary medicine therapeutics useful for treatment of chemotherapy induced GIM are summarized in Table 1.

\section{Probiotics}

Previous studies have indicated that gastrointestinal microflora may be involved in the development 
Table 1. Plant based complementary therapies for GIM

\begin{tabular}{|c|c|c|}
\hline Complementary Therapy & Effect & Reference \\
\hline Aged garlic extract & Apoptosis (Decrease) & $39,40,41$ \\
\hline Grape seed extract & Inflammation (Decrease), Myeloperoxidase activity (Decrease) & $42,43,44,45$ \\
\hline Apricot and $\beta$-carotene & Inflammatory cell infiltration (Decrease) & 50,51 \\
\hline Ellagic acid \& pumpkin seed oil & Prostaglandin E2 (Decrease), Nitric oxide (Decrease) & 52 \\
\hline Hesperidin & Inducible nitric oxide synthase, Interleukin-8 (Decrease) & 53 \\
\hline Aqueous extract of Chimonanthus nitens & Caspase 3, TNF- $\alpha$ (Decrease) & 54 \\
\hline Curcumin & Bax, IL-1 $\beta$, TNF- $\alpha$, I- $\kappa$ B (Decrease) & 57,58 \\
\hline$\beta$-glucan & Leukocyte apoptosis (Decrease) & 59 \\
\hline Saireito & Apoptosis, IL-1 $\beta$, TNF- $\alpha$ (Decrease) & 60 \\
\hline Iberogast & Histopathological features (Improve) & 61,62 \\
\hline Acteoside & Inflammation (Decrease) & 63,64 \\
\hline Mucoadhesive formulation of Bidens pilosa & Bax (Decrease), Myeloperoxidase activity (Decrease) & 65 \\
\hline
\end{tabular}

of chemotherapy-induced mucositis and diarrhoea $(66,67)$. It has been suggested that intestinal bacteria can attenuate or aggrevate GIM by influencing the intestinal inflammatory process, influencing intestinal permeability, influencing the composition of the mucus layer, influencing resistance to harmful stimuli and enhancing epithelial repair, and the activation and release of immune effector molecules (67). Mucins play an important role in maintaining the integrity of the normal intestinal flora by providing attachment sites for intestinal flora and pathogenic bacteria (68). Therefore, maintaining a healthy microbiota and mucin layer during chemotherapy treatment could minimise the complications associated with GIM. In this context, probiotic microorganisms represent a promising therapeutic option in treatment of GIM $(69,70)$. Probiotics are defined as living microorganisms which when administered in adequate amounts, exert desirable health benefits on the host (71). Probiotics are known to exert beneficial effects to the host when ingested, and therefore could be useful in controlling the intestinal microflora during chemotherapy $(72,73)$. Most commonly used probiotic bacteria include genera of Lactobacillus and Bifidobacterium. However, few strains of Enterococcus, Streptococcus, Lactococcus and certain species of non-pathogenic Escherichia strains have also been classified as probiotics (73).

Lactobacillus acidophilus administration concomitantly with 5-FU and alone for two additional days has been reported to significantly reverse the side effects of GIM (74). These include improvement in villus height-crypt depth ratio and decrease in TNF- $\alpha$ and IL-1 $\beta$ levels after 5-FU treatment (74). Probiotic mixture VSL\#3 reduced weight loss, prevented diarrhea and inhibited apoptosis in small and large intestine after treatment with irinotecan (75). Saccharomyces boulardii significantly reversed histopathological changes, reduced neutrophil infiltration and reduced concentrations of TNF- $\alpha$ and IL-1 $\beta$ after 5-FU treatment (76). Cow's milk yoghurt fermented with Lactobacillus johnsonii and Sheep's milk yoghurt containing Lactobacillus bulgaricus and Streptococcus thermophilus improved small intestinal barrier functions as determined by lactulose/mannitol ratio in MTX-induced rat models of $\operatorname{GIM}(77)$.

Orally ingested Streptococcus thermophilus attenuated MTX-induced small bowel damage in rats as indicated by non-invasive sucrose breath test (78). Probiotic derived supernatant from Escherichia coli Nissle $1971(\mathrm{EcN})$ partially protected the intestine of dark agouti rats from 5-FU induced GIM and significantly decreased cell death induced in IEC-6 cell lines after treatment with 5-FU $(79,80)$. Lactobacillus fermentum BR11 reduced jejunal inflammation as evident from reduced myeloperoxidase activity in 5-FU induced rat models of GIM (81). Pre-treatment EcN and LGG (Lactobacillus rhamnosus) supernatants lowered caspase activity, inhibited enterocyte apoptosis and loss of intestinal barrier function induced by 5 -FU treatment of IEC-6 cells (82). Oral administration of probiotics Lactobacillus casei variety rhamnosus (Lcr35) or Lactobacillus acidophilus and Bifidobacterium bifidum (LaBi) appeard to ameliorate the intestinal mucositis severity by inhibition the expressions of proinflammatory cytokines (83). Various microorganisms used as probiotics for treatment of chemotherapy induced GIM are summarized in Table 2.

\section{Miscellaneous complementary therapies}

Administration of Emu oil daily via orogastric gavage after intraperitoneally injected single dose of 5-FU improved rate of recovery from GIM (84). Significant decrease in activated neutrophil infiltration, improvement in crypt depth and villus height, decrease in acute inflammation and overall improvement in mucosal architecture in the intestine have been reported after Emu oil supplementation $(84,85)$. Lyprinol, a lipid extract derived from mussels and rich in omega-3 polyunsaturated fatty acids partially improved 5-FU induced GIM in rat models (86). Mice that received dietary supplementation with omega-3 fatty acid were associated with mucosal integrity and a reduced number of apoptotic cells in the ileum mucosa compared to the mice that received the control diet and 5-FU injection (87). 
Table 2. Probiotic based complementary therapies for GIM

\begin{tabular}{|c|c|c|}
\hline Complementary Therapy & Effect & Reference \\
\hline Lactobacillus acidophilus & TNF- $\alpha$, IL-1 $\beta$ (Decrease) & 74 \\
\hline Probiotic mixture VSL\#3 & Diarrhea, Apoptosis (Decrease) & 75 \\
\hline Saccharomyces boulardii & Neutrophil infiltration (Decrease) & 76 \\
\hline Lactobacillus johnsonii & Intestinal barrier functions (Improve) & 77 \\
\hline Lactobacillus bulgaricus & Intestinal barrier functions (Improve) & 77 \\
\hline Streptococcus thermophilus & Intestinal barrier functions(Improve) & 77,78 \\
\hline Escherichia coli Nissle 1971 & Apoptosis (Decrease) & 79,80 \\
\hline Lactobacillus fermentum BR11 & Myeloperoxidase activity (Decrease) & 81 \\
\hline Lactobacillus rhamnosus \& Escherichia coli Nissle 1971 & Caspase activity (Decrease) & 82 \\
\hline Lactobacillus acidophilus \& Bifidobacterium bifidum & Proinflammatory cytokines (Decrease) & 83 \\
\hline Lactobacillus casei variety rhamnosus & Proinflammatory cytokines (Decrease) & 83 \\
\hline
\end{tabular}

Table 3. Miscellaneous complementary therapies for GIM

\begin{tabular}{lll}
\hline Complementary Therapy & Effect & Reference \\
\hline Emu oil & Neutrophil infiltration (Decrease) & 84,85 \\
Lyprinol & Crypt cell proliferation (Decrease) & 86 \\
Omega-3 fatty acid & Mucosal integrity (Improve) & 87 \\
L-arginine supplementation & Enterocyte apoptosis (Decrease) & 88,89 \\
$\beta$-Hydroxy- $\beta$-Methylbutyrate, L-Glutamine and L-Arginine & Enterocyte apoptosis (Decrease) & 90 \\
Insulin-like growth factor-I & Histopathological parameters (Improve) & 91 \\
\hline
\end{tabular}

Dietary L-arginine supplementation decreased enterocyte apoptosis accompanied by decrease in Bax mRNA and protein expression and increased $\mathrm{Bcl}-2$ protein levels in rat model of MTX-induced GIM (88). L-arginine attenuated the histopathological score and myeloperoxidase activity promoting partial mucosal recovery, reducing inflammation and improving intestinal permeability in 5-FU induced GIM (89). Diet containing $\beta$-hydroxy- $\beta$-methylbutyrate, L-glutamine and L-arginine significantly decreased apoptosis in rats after administration of 5-FU (90). Pre-treatment with insulin-like growth factor-I in rats improved various intestinal parameters and partially attenuated features of intestinal mucositis when assessed $48 \mathrm{~h}$ after 5 -FU chemotherapy (91). Table 3 summarizes these therapies.

\section{Conclusions}

Treatment options for patients with GIM are limited, and prevention requires an understanding of the pathophysiological mechanisms underlying GIM development. Despite the debilitating symptoms of chemotherapy-induced GIM, there remains no truly effective treatment strategy capable of preventing the associated intestinal damage. In this context, the role of CAM in treatment of GIM is very critical. Therapies based on CAM have been reported to improve the symptoms of GIM. Enthusiasm for CAM use and research is clearly growing. Medline citations for alternative medicine have steadily increased from 69 citations in the 1970 s to 423 citations since 2000 (92). GIM with its varied pathobiology presents many molecular steps that can be targeted with CAM. However, the absence of rigorous scientific testing has delayed the use of CAM in mainstream medicine. In this review, many studies related to use of CAM in treating GIM have been reported. Further studies are required to optimize the use of these novel agents to alleviate the distressing symptoms of intestinal mucositis. We have much still to learn about CAM treatments in terms of efficacy, safety and cost-effectiveness. For safe treatment of chemotherapy induced GIM, a truly collaborative effort between CAM practitioners, conventional physicians and research scientists is needed.

\section{Acknowledgements}

The authour is thankful to Dr. Safrun Mahmood (PGIMER, Chandigarh), Prof. Akhtar Mahmood (Panjab University, Chandigarh), Dr. Mumtaz Anwar (University of Chicago, Illinois), and Dr. Showkat Ganie (Department of Clinical Biochemistry, University of Kashmir) for their support and suggestions.

\section{References}

1. Daniele B, Secondulfo M, De Vivo R, Pignata S, De Magistris L, Delrio P, Palaia R, Barletta E, Tambaro R, Carratù R. Effect of chemotherapy with 5-fluorouracil on intestinal permeability and absorption in patients with advanced colorectal cancer. J Clin Gastroenterol. 2001; 32:228-230.

2. Duncan M, Grant G. Oral and intestinal mucositis-causes and possible treatments. Aliment Pharmacol Ther. 2003; 18:853-874.

3. Bowen JM, Gibson RJ, Cummins AG, Keefe DM. Intestinal mucositis: The role of the Bcl-2 family, p53 and caspases in chemotherapy-induced damage. Support Care Cancer. 2006; 14:713-731. 
4. Keefe DM, Brealey J, Goland GJ, Cummins AG. Chemotherapy for cancer causes apoptosis that precedes hypoplasia in crypts of the small intestine in humans. Gut. 2000; 47:632-637.

5. Keefe DM, Gibson RJ, Hauer-Jensen M. Gastrointestinal mucositis. Semin Oncol Nurs. 2004; 20:38-47.

6. Keefe DM, Cummins AG, Dale BM, Kotasek D, Robb TA, Sage RE. Effect of high-dose chemotherapy on intestinal permeability in humans. Clin Sci (Lond). 1997; 92:385-389.

7. Elting LS, Cooksley CD, Chambers MS, Garden AS. Risk, outcomes, and costs of radiation-induced oral mucositis among patients with head-and-neck malignancies. Int $\mathrm{J}$ Radiat Oncol Biol Phys. 2007; 68:1110-1120.

8. Peterson LW, Artis D. Intestinal epithelial cells: Regulators of barrier function and immune homeostasis. Nat Rev Immunol. 2014; 14:141-153.

9. Crosnier C, Stamataki D, Lewis J. Organizing cell renewal in the intestine: Stem cells, signals and combinatorial control. Nat Rev Genet. 2006; 7:349-359.

10. Van der Flier LG, Clevers H. Stem cells, self renewal, and differentiation in the intestinal epithelium. Annu Rev Physiol. 2009; 71:241-260.

11. Potten CS, Booth C, Hargreaves D. The small intestine as a model for evaluating adult tissue stem cell drug targets. Cell Prolif. 2003; 36:115-129.

12. Booth C, Potten CS. Gut instincts: Thoughts on intestinal epithelial stem cells. J Clin Invest. 2000; 105:1493-1499.

13. Gibson RJ, Bowen JM, Inglis MR, Cummins AG, Keefe $\mathrm{DM}$. Irinotecan causes severe small intestinal damage, as well as colonic damage, in the rat with implanted breast cancer. J Gastroenterol Hepatol. 2003; 18:1095-1100.

14. Sonis ST. The pathobiology of mucositis. Nat Rev Cancer. 2004; 4:277-284.

15. Logan RM, Stringer AM, Bowen JM, Yeoh AS, Gibson RJ, Sonis ST, Keefe DM. The role of pro-inflammatory cytokines in cancer treatment-induced alimentary tract mucositis: Pathobiology, animal models and cytotoxic drugs. Cancer Treat Rev. 2007; 33:448-460.

16. Bowen JM, Gibson RJ, Cummins AG, Tyskin A, Keefe DM. Irinotecan changes gene expression in the small intestine of the rat with breast cancer. Cancer Chemother Pharmacol. 2007; 59:337-348.

17. Bowen JM, Gibson RJ, Tsykin A, Stringer AM, Logan RM, Keefe DM. Gene expression analysis of multiple gastrointestinal regions reveals activation of common cell regulatory pathways following cytotoxic chemotherapy. Int J Cancer. 2007; 121:1847-1856.

18. Chang CT, Ho TY, Lin H, Liang JA, Huang HC, Li CC, Lo HY, Wu SL, Huang YF, Hsiang CY. 5-Fluorouracil induced intestinal mucositis via nuclear factor- $\kappa \mathrm{B}$ activation by transcriptomic analysis and in vivo bioluminescence imaging. PLoS One. 2012; 7:e31808.

19. Ong ZY, Gibson RJ, Bowen JM, Stringer AM, Darby JM, Logan RM, Yeoh AS, Keefe DM. Pro-inflammatory cytokines play a key role in the development of radiotherapy-induced gastrointestinal mucositis. Radiat Oncol. 2010; 5:22.

20. Logan RM, Gibson RJ, Bowen JM, Stringer AM, Sonis ST, Keefe DM. Characterisation of mucosal changes in the alimentary tract following administration of irinotecan: Implications for the pathobiology of mucositis. Cancer Chemother Pharmacol. 2008; 62:33-41.

21. Bowen JM, Gibson RJ, Keefe DM. Cytotoxic chemotherapy up-regulates pro-apoptotic Bax and Bak in the small intestine of rats and humans. Pathology. 2005; 37:56-62.

22. Stringer AM, Gibson RJ, Logan RM, Bowen JM, Yeoh AS, Laurence J, Keefe DM. Irinotecan induced mucositis is associated with changes in intestinal mucins. Cancer Chemother Pharmacol. 2009; 64:123-132.

23. Wardill HR, Bowen JM, Al-Dasooqi N, Sultani M, Bateman E, Stansborough R, Shirren J, Gibson RJ. Irinotecan disrupts tight junction proteins within the gut: Implications for chemotherapy-induced gut toxicity. Cancer Biol Ther. 2014; 15:236-244.

24. Al-Dasooqi N, Wardill HR, Gibson RJ. Gastrointestinal mucositis: The role of MMP-tight junction interactions in tissue injury. Pathol Oncol Res. 2014; 3:485-491.

25. Kaczmarek A, Brinkman BM, Heyndrickx L, Vandenabeele P, Krysko DV. Severity of doxorubicininduced small intestinal mucositis is regulated by the TLR-2 and TLR-9 pathways. J Pathol. 2012; 226:598-608.

26. Frank M, Hennenberg EM, Eyking A, Rünzi M, Gerken G, Scott P, Parkhill J, Walker AW, Cario E. TLR signaling modulates side effects of anticancer therapy in the small intestine. J Immunol. 2015; 194:1983-1995.

27. Wong DV, Lima-Júnior RC, Carvalho CB, Borges VF, Wanderley CW, Bem AX, Leite CA, Teixeira MA, Batista GL, Silva RL, Cunha TM, Brito GA, Almeida PR, Cunha FQ, Ribeiro RA. The adaptor protein Myd88 is a key signaling molecule in the pathogenesis of irinotecan-induced intestinal mucositis. PLoS One. 2015; 10:e0139985.

28. Wardill HR, Gibson RJ, Logan RM, Bowen JM. TLR4/ PKC-mediated tight junction modulation: A clinical marker of chemotherapy-induced gut toxicity? Int J Cancer. 2014; 135:2483-2492.

29. Logan RM, Stringer AM, Bowen JM, Gibson RJ, Sonis ST, Keefe DM. Is the pathobiology of chemotherapyinduced alimentary tract mucositis influenced by the type of mucotoxic drug administered? Cancer Chemother Pharmacol. 2009; 63:239-251.

30. Stringer AM. Interaction between host cells and microbes in chemotherapy induced mucositis. Nutrients. 2013; 5:1488-1499.

31. Cario E. Innate immune signalling at intestinal mucosal surfaces: A fine line between host protection and destruction. Curr Opin Gastroenterol. 2008; 24:725-732.

32. Carvalho FA, Aitken JD, Vijay-Kumar M, Gewirtz AT. Toll-like receptor-gut microbiota interactions: Perturb at your own risk! Annu Rev Physiol. 2012; 74:177-198.

33. Shi D, Das J, Das G. Inflammatory bowel disease requires the interplay between innate and adaptive immune signals. Cell Res. 2006; 16:70-74.

34. Fernandes-Alnemri T, Kang S, Anderson C, Fitzgerald KA, Alnemri ES. Cutting edge: TLR signaling licenses IRAK1 for rapid activation of the NLRP3 inflammasome. J Immunol. 2013; 191:3995-3999.

35. Soares PM, Lima-Junior RC, Mota JM, Justino PF, Brito GA, Ribeiro RA, Cunha FQ, Souza MH. Role of plateletactivating factor in the pathogenesis of 5-fluorouracilinduced intestinal mucositis in mice. Cancer Chemother Pharmacol. 2011; 68:713-720.

36. Yasuda M, Kato S, Yamanaka N, Iimori M, Utsumi D, Kitahara Y, Iwata K, Matsuno K, Amagase K, YabeNishimura C, Takeuchi K. Potential role of the NADPH oxidase NOX1 in the pathogenesis of 5-fluorouracilinduced intestinal mucositis in mice. Am J Physiol Gastrointest Liver Physiol. 2012; 302:1133-1142. 
37. Arifa RD, Madeira MF, de Paula TP, Lima RL, Tavares LD, Menezes-Garcia Z, Fagundes CT, Rachid MA, Ryffel B, Zamboni DS, Teixeira MM, Souza DG. Inflammasome activation is reactive oxygen species dependent and mediates irinotecan-induced mucositis through IL-1 $\beta$ and IL-18 in mice. Am J Pathol. 2014; 184:2023-2034.

38. Stringer AM, Gibson RJ, Logan RM, Bowen JM, Yeoh AS, Hamilton J, Keefe DM. Gastrointestinal microflora and mucins may play a critical role in the development of 5-fluorouracil-induced gastrointestinal mucositis. Exp Biol Med (Maywood). 2009; 234:430-441.

39. Horie T, Matsumoto H, Kasagi M, Sugiyama A, Kikuchi M, Karasawa C, Awazu, S, Itakura Y, Fuwa T. Protective effect of aged garlic extract on the small intestinal damage of rats induced by methotrexate treatment. Planta Med. 1999; 65:545-548

40. Yuncu M, Eralp A, Celik A. Effect of aged garlic extract against methotrexate-induced damage to the small intestine in rats. Phytother Res. 2006; 20:504-510.

41. Li T, Ito K, Sumi S, Fuwa T, Horie T. Protective effect of aged garlic extract (AGE) on the apoptosis of intestinal epithelial cells caused by methotrexate. Cancer Chemother Pharmacol. 2009; 63:873-880.

42. Cheah KY, Howarth GS, Bastian SE. Grape seed extract dose-responsively decreases disease severity in a rat model of mucositis; concomitantly enhancing chemotherapeutic effectiveness in colon cancer cells. PLoS One. 2014; 9:e85184.

43. Cheah KY, Howarth GS, Yazbeck R, Wright TH, Whitford EJ, Payne C, Butler RN, Bastian SE. Grape seed extract protects IEC-6 cells from chemotherapy-induced cytotoxicity and improves parameters of small intestinal mucositis in rats with experimentally-induced mucositis. Cancer Biol Ther. 2009; 8:382-390.

44. Yang G, Wangm H, Kang Y, Zhu MJ. Grape seed extract improves epithelial structure and suppresses inflammation in ileum of IL-10-deficient mice. Food Funct. 2014; 5:2558-2563.

45. Yang G, Xue Y, Zhang H, Du M, Zhu MJ. Favourable effects of grape seed extract on intestinal epithelial differentiation and barrier function in IL10-deficient mice. Br J Nutr. 2015; 114:15-23.

46. Shi J, Yu J, Pohorly JE, Kakuda Y. Polyphenolics in grape seeds-biochemistry and functionality. J Med Food. 2003; 6:291-299.

47. Gu L, Kelm MA, Hammerstone JF, Beecher G, Holden J, Haytowitz D, Gebhardt S, Prior RL. Concentrations of proanthocyanidins in common foods and estimations of normal consumption. J Nutr. 2004; 134:613-617.

48. Gulgun M, Erdem O, Oztas E, Kesik V, Balamtekin N, Vurucu S, Kul M, Kismet E, Koseoglu V. Proanthocyanidin prevents methotrexate-induced intestinal damage and oxidative stress. Exptl Toxicol Path. 2010; 62:109-115.

49. Gulgun M, Karaoglu A, Kesik V, Kurt B, Erdem O, Tok D, Kismet E, Koseoglu V, Ozcan O. Effect of proanthocyanidin, arginine and glutamine supplementation on methotrexate-induced gastrointestinal toxicity in rats. Methods Find Exp Clin Pharmacol. 2010; 32:657-661.

50. Vardi N, Parlakpinar H, Ozturk F, Ates B, Gul M, Cetin A, Erdogan A, Otlu A. Potent protective effect of apricot and beta-carotene on methotrexate-induced intestinal oxidative damage in rats. Food Chem Toxicol. 2008; 46:3015-3022.

51. Yuncu M, Eralp A, Koruk M, Sari I, Bağci C, Inalöz S. Effect of vitamin A against methotrexate-induced damage to the small intestine in rats. Med Princ Pract. 2004; 13:346-352.

52. El-Boghdady NA. Protective effect of ellagic acid and pumpkin seed oil against methotrexate-induced small intestine damage in rats. Indian J Biochem Biophys. 2011; 48:380-387.

53. Acipayam C, Bayram I, Daglioglu K, Doran F, Yilmaz S, Sezgin G, Totan Ateş B, Ozkan A, Tanyeli A. The protective effect of hesperidin on methotrexate-induced intestinal epithelial damage in rats: An experimental study. Med Princ Pract. 2014; 23:45-52.

54. Liu Z, Xi J, Schröder S, Wang W, Xie T, Wang Z, Bao S, Fei J. Chimonanthus nitens var. salicifolius aqueous extract protects against 5-fluorouracil induced gastrointerstinal mucostis in a mouse model. Evid Based Complement Alternat Med. 2013; 2013:789263.

55. Arjumand W, Seth A, Sultana S. Rutin attenuates cisplatin induced renal inflammation and apoptosis by reducing NF $\kappa$ B, TNF- $\alpha$ and caspase- 3 expression in Wistar rats. Food Chem Toxicol. 2011; 49:2013-2021.

56. Gong G, Qin Y, Huang W, Zhou S, Yang X, Li D. Rutin inhibits hydrogen peroxide-induced apoptosis through regulating reactive oxygen species mediated mitochondrial dysfunction pathway in human umbilical vein endothelial cells. Eur J Pharmacol. 2010; 628:27-35.

57. Yao Q, Ye X, Wang L, Gu J, Fu T, Wang Y, Lai Y, Wang Y, Wang X, Jin H, Guo Y. Protective effect of curcumin on chemotherapy-induced intestinal dysfunction. Int J Clin Exp Pathol. 2013; 6:2342-2349.

58. Song WB, Wang YY, Meng FS, Zhang QH, Zeng JY, Xiao LP, Yu XP, Peng DD, Su L, Xiao B, Zhang ZS. Curcumin protects intestinal mucosal barrier function of rat enteritis via activation of MKP-1 and attenuation of p38 and NFkappaB activation. PloS One. 2010; 5:e12969.

59. Sener G, Ekşioğlu-Demiralp E, Cetiner M, Ercan F, Yeğen BC. Beta-glucan ameliorates methotrexate induced oxidative organ injury via its antioxidant and immunomodulatory effects. Eur J Pharmacol. 2006; 542:170-178.

60. Kato S, Hayashi S, Kitahara Y, Nagasawa K, Aono H, Shibata J, Utsumi D, Amagase K, Kadowaki M. Saireito (TJ-114), a Japanese traditional herbal medicine, reduces 5-fluorouracil-induced intestinal mucositis in mice by inhibiting cytokine-mediated apoptosis in intestinal crypt cells. PLoS One. 2015; 10:e116213.

61. Germann I, Hagelauer D, Kelber O, Vinson B, Laufer $\mathrm{S}$, Weiser D, Heinle H. Antioxidative properties of the gastrointestinal phytopharmaceutical remedy STW 5 (Iberogast). Phytomedicine. 2006; 13:45-50.

62. Wright TH, Yazbeck R, Lymn KA, Whitford EJ, Cheah KY, Butler RN, Feinle-Bisset C, Pilichiewicz AN, Mashtoub S, Howarth GS. The herbal extract, Iberogast, improves jejunal integrity in rats with 5-fluorouracil (5-FU)-induced mucositis. Cancer Biol Ther. 2009; 8:923929.

63. Díaz AM, Abad MJ, Fernández L, Silván AM, De Santos J, Bermejo P. Phenylpropanoid glycosides from Scrophularia scorodonia: In vitro anti-inflammatory activity. Life Sci. 2004; 74:2515-2526.

64. Reinke D, Kritas S, Polychronopoulos P, Skaltsounis AL, Aligiannis N, Tran CD. Herbal substance, acteoside, alleviates intestinal mucositis in mice. Gastroenterol Res Pract. 2015; 2015:327872.

65. Ávila PH, Ávila RI, Filho EX, Bastos CC, Batista AC, Mendonça EF, Serpa RC, Marreto RN, Cruz AF, Lima 
EM, Valadares MC. Mucoadhesive formulation of Bidens pilosa $L$. (Asteraceae) reduces intestinal injury from 5-fluorouracil-induced mucositis in mice. Toxicol Rep. 2015; 2:563-573.

66. Stringer AM, Gibson RJ, Logan RM, Bowen JM, Yeoh AS, Burns J, Keefe DM. Chemotherapy-induced diarrhea is associated with changes in the luminal environment in the DA rat. Exp Biol Med (Maywood). 2007; 232:96-106.

67. Van Vliet MJ, Harmsen HJ, de Bont ES, Tissing WJ. The role of intestinal microbiota in the development and severity of chemotherapy-induced mucositis. PLoS Pathog. 2010; 6:e1000879.

68. Robbe C, Capon C, Coddeville B, Michalski JC. Structural diversity and specific distribution of O-glycans in normal human mucins along the intestinal tract. Biochem J. 2004; 384:307-316.

69. Wang H, Geier MS, Howarth GS. Prebiotics: A potential treatment strategy for the chemotherapy-damaged gut? Crit Rev Food Sci Nutr. 2016; 56:946-956.

70. Prisciandaro LD, Geier MS, Butler RN, Cummins AG, Howarth GS. Evidence supporting the use of probiotics for the prevention and treatment of chemotherapyinduced intestinal mucositis. Crit Rev Food Sci Nutr. 2011; 51:239-247.

71. Reid G. The importance of guidelines in the development and application of probiotics. Curr Pharm Des. 2005; 11:11-16.

72. Quigley EM. Probiotics in the management of colonic disorders. Curr Gastroenterol Rep. 2007; 9:434-440.

73. Borchers AT, Selmi C, Meyers FJ, Keen CL, Gershwin ME. Probiotics and immunity. J Gastroenterol. 2009; 44:26-46.

74. Justino PF, Melo LF, Nogueira AF, Morais CM, Mendes WO, Franco AX, Souza EP, Ribeiro RA, Souza MH, Soares PM. Regulatory role of Lactobacillus acidophilus on inflammation and gastric dysmotility in intestinal mucositis induced by 5 -fluorouracil in mice. Cancer Chemother Pharmacol. 2015; 75:559-567.

75. Bowen JM, Stringer AM, Gibson RJ, Yeoh AS, Hannam S, Keefe DM. VSL\#3 probiotic treatment reduces chemotherapy-induced diarrhoea and weight loss. Cancer Biol Ther. 2007; 6:1449-1454.

76. Justino PF, Melo LF, Nogueira AF, Costa JV, Silva LM, Santos CM, Mendes WO, Costa MR, Franco AX, Lima AA, Ribeiro RA, Souza MH, Soares PM. Treatment with Saccharomyces boulardii reduces the inflammation and dysfunction of the gastrointestinal tract in 5-fluorouracilinduced intestinal mucositis in mice. Br J Nutr. 2014; 111:1611-1621.

77. Southcott E, Tooley KL, Howart GS, Davidson GP, Butler $\mathrm{RN}$. Yoghurts containing probiotics reduce disruption of the small intestinal barrier in methotrexate-treated rats. Dig Dis Sci. 2008; 53:1837-1841.

78. Tooley K, Howarth G, Lymn K, Lawrence A, Butler RN. Oral ingestion of Streptococcus thermophilus diminishes severity of small intestinal mucositis in methotrexate treated rats. Cancer Biol Ther. 2006; 5:593-600.

79. Prisciandaro LD, Geier MS, Butler RN, Cummins AG, Howarth GS. Probiotic factors partially improve parameters of 5-fluorouracil-induced intestinal mucositis in rats. Cancer Biol Ther. 2011; 11:671-677.

80. Wang H, Bastian SE, Cheah KY, Lawrence A, Howarth GS. Escherichia coli Nissle 1917-derived factors reduce cell death and late apoptosis and increase transepithelial electrical resistance in a model of 5-fluorouracil induced intestinal epithelial cell damage. Cancer Biol Ther. 2014; 15:560-569.

81. Smith CL, Geier MS, Yazbeck R, Torres DM, Butler RN, Howarth GS. Lactobacillus fermentum BR11 and fructo oligosaccharide partially reduce jejunal inflammation in a model of intestinal mucositis in rats. Nutr Cancer. 2008; 60:757-767.

82. Prisciandaro LD, Geier MS, Chua AE, Butler RN, Cummins AG, Sander GR, Howarth GS. Probiotic factors partially prevent changes to caspases 3 and 7 activation and transepithelial electrical resistance in a model of 5-fluorouracil-induced epithelial cell damage. Support Care Cancer. 2012; 20:3205-3210.

83. Yeung CY, Chan WT, Jiang CB, Cheng ML, Liu CY, Chang SW, Chiang Chiau JS, Lee HC. Amelioration of chemotherapy-induced intestinal mucositis by orally administered probiotics in a mouse model. PLoS One. 2015; 10:e138746.

84. Lindsay RJ, Geier MS, Yazbeck R, Butler RN, Howarth GS. Orally administered emu oil decreases acute inflammation and alters selected small intestinal parameters in a rat model of mucositis. Br J Nutr. 2010; 104:513-519.

85. Mashtoub S, Tran CD, Howarth GS. Emu oil expedites small intestinal repair following 5-fluorouracil-induced mucositis in rats. Exp Biol Med (Maywood). 2013; 238:1305-1317.

86. Torres DM, Tooley KL, Butler RN, Smith CL, Geier MS, Howarth GS. Lyprinol only partially improves indicators of small intestinal integrity in a rat model of 5-fluorouracil-induced mucositis. Cancer Biol Ther. 2008; 7:295-302.

87. Generoso Sde V, Rodrigues NM, Trindade LM, Paiva NC, Cardoso VN, Carneiro CM, Ferreira AV, Faria AM, Maioli TU. Dietary supplementation with omega-3 fatty acid attenuates 5 fluorouracil induced mucositis in mice. Lipids Health Dis. 2015; 14:54.

88. Koppelmann T, Pollak Y, Mogilner J, Bejar J, Coran AG, Sukhotnik I. Dietary L-arginine supplementation reduces methotrexate-induced intestinal mucosal injury in rat. BMC Gastroenterol. 2012; 12:41.

89. Leocádio PC, Antunes MM, Teixeira LG, Leonel AJ, Alvarez-Leite JI, Machado DC, Generoso SV, Cardoso VN, Correia MI. L-arginine pretreatment reduces intestinal mucositis as induced by 5 -FU in mice. Nutr Cancer. 2015; 67:486-493.

90. Alsan Cetin I, Atasoy BM, Cilaker S, Alicikus LZ, Karaman M, Ersoy N, Demiral AN, Yilmaz O. A diet containing beta-hydroxy-beta methylbutyrate, L glutamine and L-arginine ameliorates chemo-radiation induced gastrointestinal injury in rats. Radiat Res. 2015; 184:411-421.

91. Cool JC, Dyer JL, Xian CJ, Butler RN, Geier MS, Howarth GS. Pre-treatment with insulin-like growth factor-I partially ameliorates 5 -fluorouracil induced intestinal mucositisin rats. Growth Horm IGF Res. 2005; 15:72-82.

92. Tillisch K. Complementary and alternative medicine for functional gastrointestinal disorders. Gut. 2006; 55:593596.

(Received September 8, 2016; Revised September 30, 2016; Accepted October 6, 2016) 